\title{
University as a Sociocultural Phenomenon: the Past and the Present
}

\author{
Natalia M. Pankova ${ }^{a}$, Natalia N. Kabanova ${ }^{a^{*}}$, Anna A. Kornienko ${ }^{a}$, Vladimir A. \\ Ponomarev $^{\mathrm{a}}$ \\ * Corresponding author: Natalia N. Kabanova. Tel.:+79138807823, e-mail: natkab@tpu.ru
}

${ }^{a}$ Tomsk Polytechnic University, 30 Lenin av., Tomsk,634050,_Russia,pankova_natalia@tpu.ru,+7913525346

\section{http://dx.doi.org/10.15405/epsbs.2016.02.37}

\section{Abstract}

We carried out the review of the main educational strategies which present the basis of university education in antiquity, in the medieval period and at present. The educational model created during the antique period was based on ideals of beauty and harmony, that assumed an equivalence of spiritual and corporal in personality formation as it is demanded by the nature. In philosophy of education in the medieval period there was an idea of person's transformation through education and belief by means of classical literature which was considered as a timeless knowledge source. The university was thought of as educational institution where it is possible to approach to universal knowledge. We consider that in modern society its development has transitive nature. The foundation of the educational process is not the universal knowledge, but the skill to find bearings in fast-changing knowledge stream, to adapt and find opportunities for self-fulfillment under the conditions of continuous change. In the single information and educational space it became possible to make educational process continuous as a condition of person's improvement. We conceive the idea of continuous or lifelong learning as the necessary and natural process acting as a precondition of forming integral personality and social wellbeing.

(C) 2016 Published by Future Academy www.FutureAcademy.org.uk

Keywords: University; higher education; adult education; wellbeing; globalization; knowledge society; fair society.

\section{Introduction}

The anthropological revolution in philosophy was connected with a name of the Ancient Greek philosopher Socrates who put forward the quote "Know yourself", having pointed to the importance of a person in the world. It became the basis of formulating the educational strategy which has not lost the importance even in the modern world.

The educational model formed in the antique period was based on ideals of beauty and harmony that involved an equivalence of spiritual and corporal development. "A sound mind in a sound body" - the 
great Greek philosopher Plato spoke, confirming that idea. This principle is the cornerstone of the educational and learning processes assuming the harmony of soul and a body, the world of ideas and the world of things.

In poleis of Ancient Hellas there were both state and private educational institutions, and the process of knowledge acquisition was considered as a matter of national importance as it was essential not only to teach young people to any craft, but also provide a background for formation of the free Hellene citizenship.

At that particular period the three-level education system started its formation. The first level primary school (Didascaleion) assumed studying mathematics and literature, music and fine arts. The second level was grammar school. It was supplemented by advanced studying of general subjects, and studying astronomy and philosophy along with physical development. The final stage of educational process had to be in the gymnasium (Gymnasia) where young people mastered such sciences as logic, rhetoric, ethics, etc. Gymnasiums became the centers of spiritual life of poleis. Plato's Academy and Aristotle's Lyceum made their founders world famous (Plato, 1945, Bussell, 1896).

\subsection{Classical University model formation}

In ancient tradition a man was presented as a living being dependent on supreme forces which can be perfected during the process of striving to know the truth, but not capable to reach total perfection. According to Socrates, the best way to educate a person is to help a student to recollect the knowledge the soul knew earlier, but not to persuade in something. In Plato's philosophy the idea of education was fulfilled as a process of knowing the truth embodied in the idea of the highest Good. Moreover, the notions education and upbringing in Plato's conceptual idea were coincided.

Aristotle alternatively to Plato specified that the process of education had to be focused on receiving truth which was understood as the correct display of reality in the consciousness of a person. It was Aristotle who one of the first directed to achieve harmony of physical and spiritual formation of the personality as it was demanded by the nature. It was important to teach young people to think independently. That understanding of education and truth became classical and was used at universities later.

Thus, the ancient philosophy formed the basis of the curriculum aiming to achieve inner harmony.

In medieval philosophy there was a little different approach to a problem of education. Augustine Aurelius formulated the bases of religious education system under which the knowledge had to lead to the true belief. In philosophy of education in medieval period the idea of transforming a person through education, upbringing and studying started forming. Those were education and belief through which a person came to understanding of freedom and perfection.

Both antique and Christian traditions had impact on formation of medieval education system. The church postulates were the basis of studying. Educational institutions were subdivided into two types almonry schools which trained both clergy for church service and laymen who did not intend to be given to service of God in the future, and cathedral schools which trained clergymen.

Curriculum at medieval schools was focused on the system developed in the antiquity. Some complex of sciences was developed at that period. It was necessary for further studying philosophy, 
http://dx.doi.org/10.15405/epsbs.2016.02.37

eISSN: 2357-1330 / Corresponding Author: Natalia N. Kabanova.Email: natkab@tpu.ru

Selection and peer-review under responsibility of the Organizing Committee of the conference

later it was called "The Seven Liberal Arts". In the Middle Ages the doctrine about seven liberal arts was formulated by Martianus Capella in the Vth century AD.

The given complex was presented by two directions - trivium and quadrivium. Trivium consisted of such subjects as grammar, dialectics and rhetoric, and the quadrivium consisted of geometry, arithmetic, astronomy and music. Later, approximately at the end of the XIIth century, cathedral schools were transformed into universal schools which were a prototype of modern universities. Disciplines of a trivium and a quadrivium were taught at the first level of university curriculum, at the faculty of arts, in addition to philosophy and other sciences (Chanda, J., 1998).

Studying classical literature, not only religious, but also art was the basis for curriculum, it was considered as a knowledge source out of time. It did not seem to be possible to become a person in the true sense of the word without mastering that knowledge.

While spreading universities through the territory of Europe its biggest part became the owner of new European cultural tradition. Each university had privileges which were granted to it by the Pope and the emperor. They were for university as a protection and a guarantee of further development. The rector was the official head of university who was elected annually. At medieval university 4 faculties were the main: legal, theological, medical and faculty of arts.

Appearing of the first universities in Europe is connected with such factors as prosperity of trade relations, formation of economy, growth of the cities and people's wellbeing. The ancients gave us samples of a combination of scientific knowledge, studying and civil education. The university was thought as an educational institution where it was possible to come closer to the universal knowledge assuming a combination of all types of knowledge.

The term "university" is originated from Latin universitas means a set in modern option it is a body of all types of knowledge. In modern understanding the university is the highest professional and scientific institution with departments (faculties) on various social and natural sciences, pedagogical and technical directions of training specialists. Those higher educational institutions which were universities in the last century, it is accepted to name classical, though this designation, in our opinion, is not quite correct. The term "classical university" in relation to universities of the medieval period was applied rather in the meaning of "primary or acting as an example, criteria to compare", also as for the classic concept of truth (Steen, 1989).

We consider the classical university as a difficult educational system which characteristic features are the high level of students and teachers training, and an optimum combination of the offered directions of training: natural-science and humanitarian disciplines that allows to confirm formation alumni's creativity and maintenance of cultural and moral values that makes classical university the center of science and culture development.

Therefore, at universities scientists are engaged in scientific researches and giving students the highest scientific knowledge. This is the primary task of university to give young people scientific education. As a result neither teachers nor lawyers or officials, should graduate from the university but the people who gained theoretical knowledge and trained for scientific activity in exact field.. That competence was expressed in enabling to feel confident in certain area and to be able to use the gained knowledge at the right time. 


\subsection{Modern universities}

In the second part of the XXth century the unilinear directed progressive movement came to conclusion in the world. According to the changes happened, the new model of life, so-called "society of knowledge" started its formation in Russia. That was the reflection of worldwide trend in accepting not unidirectional, but various, unlimited with borders constant movement. Development of society began to have transitive, transitional nature and it was necessary to learn how to live under the constant transition (Hayek, 2002).

The essential changes in the system of the higher education happened in the XXIst century in Russia. The instability time has come for classical universities. One world outlook leaves, another one that meets the requirements of time has come. The classical university curriculum was aimed to beauty and logic nature of scientific theory. In new educational model the information forms the basis of educational process. It allows to be guided in rapidly-changing stream of knowledge, to adapt and find opportunities for self-fulfillment in condition of permanent change. (Pogukaeva, 2015, Ageev \& Ageeva, 2015).

With the availability of single information and educational space such educational model as lifelong learning was formed as the Internet gives opportunity to communicate a teacher with students who are far apart via sending texts, using voice negotiations system (maintaining the videoconferences which carries out an exchange speech and a video information). The Internet acts as important means of carrying out discussions, an exchange of opinions on various issues and influences the development of forms and teaching methods.

In the modern world it is considered a wide range of conceptual educational models. They are concepts of research university, university as regional academic and culture complex (regional university), passionate university, entrepreneurial university and many others at which some kind of synthesis of liberal and pragmatic educational tendencies is carried out. The idea of lifelong learning receives special importance that is thought of as a necessary and quite natural process acting as a precondition of formation of the complete integral personality and social wellbeing (Brylina, 2014).

Lifelong learning is understood as a process of creating an integral personality during all human life according to needs of society based on the use of the state and social institutions. It became a necessity in the modern world according to the progress in science and technologies. Continuous education lifelong learning provides conditions for constant personal and career development.

The opportunity of applying knowledge itself began to be understood a little differently. Nowadays the target is not practical usefulness of applying expertise, knowledge and skills rather than a person's self-improvement, ability to compare new knowledge with have already had and ability to predict future direction for development. Social wellbeing to a large extent is defined by the possibility of people to adapt for constantly changing conditions and to feel easy in this changing world. The flexible education system as one of important factors of social wellbeing can help the person to control these processes.

\section{Methods}


We conducted a review of the literature to solve the research questions. All the results of the literature review had been thoroughly analyzed.

\section{Results}

Each education model presented above has its weaknesses and strengths. Thus, we propose a model of a modern university, which corresponds to the requirements of time and students. As can be seen from the above, the modern leading university is a scientific and at the same time educational and educating establishment. The main idea and the purpose of each faculty is not only to give steady scientific knowledge to students in a certain sequence, but also to reveal methods and techniques of scientific thinking which led to the discovery of the truths of science. It is the way that can lead to new scientific discoveries and after having learned the use of these methods, can apply them to solve special issues. It is necessary to give to students throughout all their lives the opportunity to develop scientific curiosity, ability to scientific thinking and creativity if there is a certain reservoir of basic knowledge.

\section{Conclusion}

Summing up the given results, we should note that all transformations in universities must be of strategic nature. The great importance which is attached to rankings, to indicators of success and relevance in the modern world, does not correspond to all aspects of university life (Altbach, 2012, Salmi, 2007). The close attention to research activity and publication productivity can affect curriculum negatively, quality of teaching which is difficult to measure by quantitative methods. The reality is that the requirement of fast results does not promote the development of innovative and longterm researches. Creativity and passion for knowledge, striving to self-improvement should not be measured by money; moreover, the prevalence of pragmatic tendency at university, with inevitability leads unavoidably to crisis of creative thinking

\section{Acknowledgements}

We would like to express gratitude to the department of history and philosophy of science and technique for comments an earlier version of this paper. In addition, we would like to express gratitude to Tomsk Polytechnic University for organizing «International Conference on Research Paradigms Transformation in Social Sciences 2015», as well as to the authors, who contributed to this research on the basis of the project of Evaluation and enhancement of social, economic and emotional wellbeing of older adults under the Agreement № 14.Z50.31.0029.

\section{References}

Plato. The republic of Plato. - New York : Oxford University Press, 1945. - T. 30. - C. 175-203.

Bussell F. W. The School of Plato: Its Origin, Development, and Revival Under the Roman Empire. - Methuen, 1896.

Chanda, J. (1998). Art history inquiry methods: Three options for art education practice. Art education, 17-24.

Steen, L. A. (1989). Teaching mathematics for tomorrow's world. Educational Leadership, 47(1), 18-22

Hayek, F. (2002) A road to Serfdom. London. URL: https://mises.org/sites/default/files/Road\%20to\%20serfdom.pdf

Pogukaeva, N. (2015). Cognitive management in the information society context. Procedia-Social and Behavioral Sciences. 166, 456-459

Ageev, I., Ageeva, V. (2015). Urban lifestyle as an element of consumption ideal and economic wellbeing: meaning-changing transformation from Soviet period to modernity. Proceedings of the international conference 
eISSN: $2357-1330$

Selection \& Peer-review under responsibility of the Conference Organization Committee

on research paradigms transformation in social sciences. Procedia - Social and Behavioral Sciences, 166, $24-$ 29.

Brylina, I., and all. (2014) Transdisciplinarity as a new form of fundamental knowledge in the system of higher education, Psychology and Psychiatry. Education and Educational research, 1, 1005-1012

Altbach P. and Salmi J. (2012) International advisors - a valuable asset or an added expense? University World News. Available at: http://www.universityworldnews.com/ article.php?story=20120411172913611 (access date: 10.10.2015).

Salmi J., Froumin I. (2007) Russian universities in the world competition, Issues in Education. Vol. 3, p. 5.

Minin M. (2009) Teaching Foreign Languages for Technical University Pedagogical Staff by the Example of Professional Development System of Tomsk Polytechnic University, Q2 of E2 - Quality and Quantity of Engineering Education, 38th International IGIP Symposium. Graz, Austria, 6-9 September 2009, pp. 130-131. 